\title{
Alguns usos da psicologia no Exército Brasileiro de 1930 a 1960: os cursos
}

\author{
Some uses of Psychology in the Brazilian Army from 1930 to 1960: the \\ courses
}

\author{
Ana Maria Jacó-Vilela \\ Dayse de Marie Oliveira \\ Thais Lohana Lins \\ Maíra de Souza Cerqueira dos Anjos \\ Universidade do Estado do Rio de Janeiro \\ Brasil
}

\begin{abstract}
Resumo
O presente trabalho tem como objetivo compreender a presença da psicologia dentro do Exército Brasileiro nos anos de 1930 a 1960. Sua ênfase principal se situa na apresentação dos cursos de psicologia que eram ministrados no Exército nesse período. Para isso, utilizamos a metodologia histórica, privilegiando as fontes primárias encontradas em bibliotecas e arquivos especializados, principalmente do Exército. Nestas fontes, observou-se que a psicologia esteve presente em todo o período, de maneira variável. Inicialmente, encontramos referências à psicologia experimental. Depois, há um grande período cuja interesse se situa na psicotécnica,. Finalmente, após a II Guerra Mundial, instaura-se a psicologia social, justificada, principalmente, pelo estudo da questão da liderança. Observase pois que a trajetória da psicologia no Exército acompanha sua história no Brasil.
\end{abstract}

Palavras-chave: história da psicologia; psicologia militar; psicologia aplicada

\begin{abstract}
This article aims to understand the presence of Psychology within the Brazilian Army from 1930 to 1960 , with emphasis on the psychology courses that were taught in the army during these decades. For such purpose, the research was based on the historical methodology, pursuing to use, mostly, the primary sources found in archives and specialized libraries, most of them within the Army itself. In those sources, we were able to observe that psychology was a current subject during all the period, in variable ways. At first, we found references to the experimental psychology. Then, for a long period, the main interest was in the psychotechnical field. Finally, after World War II, social psychology is established, which is justified afterwards, mainly, by the study of the matter of leadership. It is, therefore, observed that the trajectory of psychology in the Army follows its history in Brazil.
\end{abstract}

Keywords: history of psychology; military psychology; applied psychology

É comum entre os historiadores a noção de que o fato histórico não existe per se, mas é construído retrospectivamente a partir de abordagens diversas, como por exemplo, a da proveniência (as condições culturais, econômicas, sociais, políticas) que possibilitou sua emergência, que ocorresse tal acontecimento e não outro (Jacó-Vilela, 2009). Embora esta perspectiva esteja presente em quase toda a historiografia atual das ciências, especialmente o estudo da história da ciência em países periféricos 
passa necessariamente, a nosso ver, por colocar em cena questões políticas, de dependência, de autonomia ou de colaboração e intercâmbio em relação ao centro, entendido aqui como alguns países da Europa e os Estados Unidos. Países europeus colonizaram "novos mundos", no processo que perdurou do século XV ao XIX. Neste percurso, a cultura europeia expandiu-se para outros continentes, incluindo, no que aqui nos interessa, a universalização do conceito de ciência, de seus métodos e modelos. Como sabemos, os países colonizados serviram, numa primeira fase, de matéria prima para o conhecimento científico que estava sendo desenvolvido nos países centrais. São os religiosos, os viajantes e os naturalistas que forneceram informações sobre a flora, a fauna, e os seres humanos encontrados na América, na África, na Ásia, na Oceania, permitindo a entrada de novos tipos nos imensos sistemas classificatórios então construídos. Como exemplo, no caso brasileiro, temos os cientistas alemães Johan Baptist von Spix (1781-1826) e Karl Friedrich Philip von Martius (1794-1868). Eles realizaram grande viagem pelo interior do país, no início do século XIX, estudando a população rural, até então pouco conhecida. Este tipo de atividade é muito bem analisada por Safier (2010).

Tal estratégia, se é ratificadora do modelo de ciência que está se afirmando, ao mesmo tempo desqualifica, como não científicos, os saberes dos povos daqueles continentes que, diz-se, foram descobertos em determinadas datas pelos europeus. Se a nova forma de produzir conhecimento torna-se bem recebida nos países colonizados, isto é uma das consequências, sem dúvida, do processo colonizador (Fanon, 1968). Entretanto, a pergunta que se faz necessária é: uma vez apreendido o modelo científico, existe novo tipo de produção de conhecimento (para além dos esquemas estrangeiros assimilados) nesses países outrora colonizados, que agora pertencem a um grupo que recebeu, ao longo do tempo, denominações diversas, como Terceiro Mundo, subdesenvolvidos, em desenvolvimento, periféricos categorias estas que indicam que estes países ainda não estão "lá", no lugar de contribuição decisiva à ciência?

Uma das respostas a esta questão é o chamado "modelo de Basalla" (Basalla, 1967). Este historiador norte-americano prevê que a produção científica em países periféricos passa necessariamente por três estágios. No primeiro, conforme citamos acima, cientistas europeus fazem coleta de dados nas colônias e, ao retornarem a seus países, estudam as informações obtidas e elaboram conclusões. No segundo, começa a se desenvolver uma ciência colonial, os pesquisadores dos países centrais treinam os pesquisadores das ex-colônias, possibilitando assim que, em um terceiro momento, ocorra produção independente naqueles países, através da criação de instituições de ensino e de pesquisa. 
Mas este modelo não é aceito por muitos historiadores da ciência, principalmente por seu caráter evolucionista. Stepan (1976), por exemplo, ao analisar o desenvolvimento da ciência brasileira no século XIX, discorda de Basalla. Entende que esta pode ter sido a situação em países como os Estados Unidos e a Austrália, colônias da Inglaterra, mas não é a daqueles outros cujas matrizes coloniais estavam há muito tempo afastadas das principais correntes do desenvolvimento científico internacional. Nestes, constrói-se um pensamento científico próprio que não tem, todavia, maior potencial de circulação e debate tanto nos países europeus quanto, posteriormente, nos Estados Unidos, que se tornam a referência a partir da segunda metade do século XX. Um dos empecilhos, principalmente no caso brasileiro, é decorrente do idioma. Portugal, grande império desbravador, perdeu aos poucos seu poderio econômico, político, militar e cultural a partir do século XVII, tornando o idioma português restrito a parcela da população mundial, situada notadamente nos países periféricos.

Entretanto, a questão principal é a assunção, por parte também de pesquisadores nativos, do papel subalterno, colonizado, da ciência nacional em relação à contribuição incisiva dos pensadores estrangeiros, enfatizando o caráter de "reprodução" dos modelos externos em nossa produção científica. Parece, pois, que a dicotomia "centro $x$ periferia" não é uma questão ultrapassada, haja vista, por exemplo, a constante ênfase da CAPES nos processos de internacionalização dos Programas de Pós-Graduação (internacionalização normalmente entendida como reconhecimento entre os pares dos países "centrais"), nosso interesse cotidiano em estadas de aperfeiçoamento nestes países, nossas bibliografias utilizando majoritariamente, em muitos casos, pesquisadores de centros de pesquisas desses países, o envio de alunos para lá, o interesse em publicar em revistas de lá - em contrapartida, por exemplo, com o parco interesse nas mesmas atividades em parceria com países latinoamericanos ou africanos.

Por outro lado, diversos autores vêm alertando, já há algum tempo, que a recepção de novas ideias e práticas em contextos diferentes daqueles em que foram produzidas não corresponde, em quase todos os casos, a uma "reprodução" daquilo que foi construído em outro lugar (ver, por exemplo, Restrepo Forero, 2000). Tratase, como já afirmava Schwarz (1977), de "ideias fora do lugar" e que, por isto mesmo, são apropriadas e se transformam em outras ideias em sua nova ambiência. Schwarz segue, neste ponto, uma linha de interpretação da cultura brasileira que se baseia nas contradições e ambiguidades existentes nas relações entre senhores e escravos, senhores e homens livres (os "agregados"), homens livres e escravos, recorrendo às condições de formação da sociedade brasileira moderna para explicar o seu modo de funcionamento atual. 
Da mesma forma o faz Sanchis (1995, 2001). Embora se dirigindo especificamente ao sincretismo religioso, suas conclusões podem, ao nosso ver, serem estendidas também à produção científica. Sanchis compara o sincretismo religioso brasileiro com o europeu: enquanto este último foi sempre um apagamento da religião anterior (a religião romana utilizando-se das práticas celtas, mas destruindo a lembrança da religião celta, a religião católica fazendo o mesmo com a religião romana), no caso brasileiro o sincretismo significa uma mistura, a preservação de elementos das religiões envolvidas. Sanchis considera como origem desse tipo especial de sincretismo as bandeiras, quando portugueses, tupis e africanos encontravam-se em lugares desconhecidos, enfrentando não sabiam que perigos e orando, juntos, para seus deuses particulares ${ }^{1}$.

Estes autores representam, pois, uma contribuição à atual discussão no campo da história da ciência acerca da pertinência de se dedicar mais atenção ao que vem sendo denominado de "ciência nativa", ou "local", tendo em vista um dos temas principais dessa nova historiografia referir-se tanto à produção de conhecimento nativo quanto à circulação do conhecimento e às formas de recepção das ideias e práticas geradas nos países centrais pelos países periféricos, ideias que se configuram, então, como novas produções.

De qualquer forma, pode-se dizer que o modelo tradicional centro-periferia encontra-se ainda sob revisão, como diz Svasundaram (2010): "New global histories of science will be characterized by critical reflection on the limits of generalization, as well as a creative adoption of new sources, methods and chronologies, in an attempt to decenter the European history of science" (p. 95).

Este trabalho decorre de investigação que visava responder a uma pergunta: a psicologia desenvolvida no Rio de Janeiro entre as décadas de 1930 e 1960 tinha como base teórico-metodológica o comportamentalismo? Se sim, como este se apresentava? Se não, o que existia? Em que campos?

Esta pergunta decorre da questão que se colocava na pesquisa mais ampla que gerou este trabalho em que, apoiando-nos em manuais de história da psicologia, vimos que a psicologia mainstream considerava o período de 1930 a 1950 como as décadas de outro do comportamentalismo (Leahey, 2005).

Neste sentido, entendíamos que muito havia ainda a ser investigado, pois, se verificamos a historiografia da psicologia sobre o período, encontramos que ela se detém principalmente em apontar o papel da psicologia na educação (ver Antunes, 2002; Campos, 2004), chamando a atenção tanto para a Pedagogia Científica quanto

\footnotetext{
${ }^{1}$ Sanchis não se refere à participação forçada de negros e índios no projeto de busca de riquezas por parte dos portugueses. De qualquer forma, a ideia de "mescla" na cultura brasileira está presente em diferentes autores, como na obra seminal de Gilberto Freyre, publicada em 1933 (Freyre, 1997).
} 
para a Escola Nova, com menções frequentes aos nomes de Maria Montessori e Edouard Claparède (este, sem dúvida, muito mais citado que Montessori; ver, a respeito, Nassif \& Campos, 2005). E, se consultamos a historiografia da educação (por exemplo, Monarcha, 2009), verificamos que também aí encontramos a relevância da ciência psicológica para a Educação se firmar como um campo científico ${ }^{2}$. Neste campo, portanto, a presença do behaviorismo não era predominante.

Procuramos então levantar os indícios de inserções da psicologia em campos ainda não desvendados, pequenos sinais, sugestões de caminhos que a Psicologia teria percorrido e que ainda eram desconhecidos, indícios que apareceram em nossas pesquisas anteriores. Um destes pequenos sinais é o fato de que um grande nome da psicologia no Rio de Janeiro, o Professor Antonio Gomes Penna (1917-2010), tenha sido também professor de Psicologia na Aeronáutica e no Exército, tendo inclusive escrito um Manual de Psicologia para as Forças Armadas, infelizmente não publicado (Penna, 1992). Sabemos também que havia militares médicos no Laboratório de Psicologia da Colônia de Psicopatas do Engenho de Dentro, dirigido pelo psicólogo polonês Waclaw Radecki (1887-1953) (Centofanti, 1982). Segundo Olinto (1944/2004), "um outro laboratório de Psicologia Experimental foi montado no departamento médico da aeronáutica do Exército, onde se destacaram as pesquisas de A. Bretas" (p. 27). Se nos lembrarmos que o Laboratório de Radecki havia sido transformado em Instituto de Psicologia em 1932 e logo em seguida desativado, não parece ser simples coincidência a data de criação do Laboratório no Departamento de Aviação (nome correto do órgão) do Exército. Como pouco mais sabíamos a respeito, optamos por dirigir nossa investigação para as relações entre psicologia e as Forças Armadas no período assinalado - 1930-1960 -, esta segunda data sendo o recorte final de nossas investigações.

Uma questão que se apresentou, então, foi o porquê de não haver investigação sobre a história da psicologia nas Forças Armadas. Os descritores que utilizamos para pesquisa nas bases Pepsic e Scielo, bem como no catálogo da Biblioteca Nacional (Psicologia e Exército, Psicologia e Aeronáutica, Psicologia e Marinha, Psicologia e Forças Armadas) não ofereceram dados relevantes à nossa investigação encontramos, por exemplo, um artigo de Rosa e Hutz (2008) sobre o bem-estar subjetivo de cadetes do Exército Brasileiro. Conhecemos um único trabalho que tangencia este tema, a tese de doutorado de Cristianne Carvalho que, investigando a história da psicologia dos esportes, utilizou, como uma de suas fontes, a revista de

\footnotetext{
2 Sem dúvida, é importante, neste contexto, o relevo dado por Lourenço Filho (1930/2004) em seu livro Introdução ao estudo da Escola Nova à Psicologia como uma das "bases científicas" da Escola Nova, ao lado da Biologia e da Estatística.
} 
Educação Física da Escola de Educação Física do Exército (Carvalho, 2012), onde encontrou uma forte presença da psicologia.

Perguntamo-nos se esta ausência decorreria do imaginário sobre as Forças Armadas como uma instituição fechada, situada ao largo da vida civil de cada um de nós. Este fechamento implicaria, por exemplo, a dificuldade de acesso às informações. Outra possibilidade seria que a existência de "psicotécnicos" no Exército levasse à conclusão de que a psicologia nas Forças Armadas se restringiria ao período áureo da psicotécnica e, como tal, estaria coberto pelos estudos a seu respeito, como o de Motta (2004)

Estas questões, junto com aqueles indícios mencionados acima, nos levaram a nos perguntar o que seria, exatamente, o entendimento de psicologia nas Forças Armadas. Haveria interesse por psicologia? Por que tipo de psicologia? Este interesse acompanhava o que se desenvolvia em outros países, notadamente os Estados Unidos, ou estava mais próximo ao percurso histórico da psicologia no Brasil, conforme narrado por diferentes autores (por exemplo, Antunes, 1999; Jacó-Vilela, 2012)?

Assim, tendo em vista o vasto campo que configura as Forças Armadas, optamos por iniciar nossa investigação com o Exército Brasileiro. Este texto visa apresentar algumas inserções da psicologia nesta instituição entre os anos de 1930 a 1960, com especial destaque aos cursos de psicologia ali ministrados

Nossa perspectiva de investigação recebe a influência de alguns autores e modos de pensamento. Assim, concordamos com De Certeau (2000) sobre a necessidade do pesquisador reconhecer o lugar de onde fala - lugar geográfico, institucional, de pertencimento a redes. Esta questão nos levou à proposição de Danziger de histórias policêntricas, várias histórias locais coexistindo (Danziger, 1996). Entretanto, consideramos que o modelo policêntrico proposto por este autor, se bem permite espaço para as histórias desenvolvidas pelos países periféricos, nem sempre ilumina as relações de dominação existentes neste campo. Assim, se consideramos que nossos trabalhos referem-se ao nosso local - de origem, de investigação consideramos também que fazem parte do que se convencionou chamar de "estudos subalternos" ou "pós-coloniais" ou "decoloniais" (Alves e Delmondez, 2015; Spivak, 2010) - o que, aliás, as interpretações de Schwarz $(1977)$ e Sanchis $(1995,2001)$ já nos indicavam.

\section{Metodologia}

Este trabalho seguiu metodologia básica da investigação histórica. Nosso enfoque refere-se à inserção e às mudanças na psicologia assumida pelo Exército na primeira 
metade do século XX, depois da I Guerra Mundial, quase iniciando o Governo Vargas, e indo até pouco depois do término da II Guerra Mundial. Neste sentido, recorre a fontes primárias que foram buscadas em arquivos e bibliotecas especializadas. Numa tentativa de catalogação, trata-se, no campo da história das ciências, de uma história institucional (por se referir ao Exército) bem como de uma história educacional (por seu objeto serem os cursos de psicologia ministrados naquela instituição). Entretanto, a inclusão em uma determinada categoria é, muitas vezes, uma tentativa procustiana, visto a realidade (e a investigação) não necessariamente aceitarem seus limites. Como diz Barros (2004):

Nota-se não raramente uma grande confusão entre algumas destas modalidades de História, e uma expressiva dificuldade dos interessados em História em situar um trabalho historiográfico qualquer dentro de um destes campos. Veremos que na verdade isto não é possível, já que a ampla maioria dos bons trabalhos historiográficos situa-se na verdade em uma interconexão de modalidades (p. 17).

Por outro lado, o trabalho pertence ao campo da utilização de fontes primárias. Em nosso caso, foram buscadas em arquivos e bibliotecas especializadas, com ênfase, neste texto, a um único acervo, qual seja o Arquivo Histórico do Exército (AHEx). Este está localizado no Palácio Duque de Caxias, no Rio de Janeiro. Nele estão depositados documentos produzidos pelo Exército que são armazenados tão logo recebam designação como arquivos históricos. O Boletim do Exército, em todas as suas edições, encontra-se lá preservado, bem como as pastas com as alterações das fichas dos militares já falecidos, os almanaques das forças militares, mapas, programas de cursos oferecidos pelo Exército etc.

Tendo em vista o desconhecimento do campo - o uso da psicologia no Exército -, optou-se por um levantamento extensivo no Boletim do Exército no período de 1927 (quando consta que Radecki teria dado o primeiro curso à instituição) até 1962 (quando a profissão de psicólogo e os cursos de psicologia foram regulamentados).

Para tanto, tivemos que solicitar autorização ao Diretor do AHEx. A resposta foi rápida e o atendimento muito bem feito. O encarregado do Arquivo é um militar formado em História, com muito interesse por pesquisas nesta área. Observamos que, no período de nossa investigação, outros pesquisadores também estavam presentes, em busca de subsídios acerca de outros temas.

A coleta de dados foi feita por bolsistas de iniciação científica, supervisionados por duas pesquisadoras da equipe. 
A orientação era solicitar os Boletins ano a ano (a partir de $1927^{3}$ ), realizar uma leitura flutuante de cada um e anotar todos os dados relevantes, a partir do uso de determinadas palavras ou expressões, quais sejam: psicologia, psicotécnica, exame médico, exame psicológico, bem como referências aos militares que, segundo Olinto (1944/2004) e Centofanti (1982) criaram o Laboratório de Psicologia no Departamento de Aviação do Exército.

\section{Resultados}

Encontramos e catalogamos registros de processos de seleção de candidatos ao ingresso no Exército; a regulamentação das instruções para a conduta e a inspeção de saúde dos militares; os currículos dos cursos de aperfeiçoamento; as informações sobre a criação dos diversos órgãos e sobre os militares envolvidos na consolidação da presença da psicologia no Exército. Neste último caso, solicitamos à direção do Arquivo as pastas respectivas, com as alterações funcionais de cada um desses militares, mas isto não é objeto deste trabalho.

Fizemos, como dito, um levantamento extensivo do Boletim do Exército, coletando dados em todos os volumes de 1927 a 1962, totalizando um período de 36 anos, o que nos deu importantes informações, entre elas sobre cursos de psicologia nas instituições de ensino do Exército. Optamos por dedicar este artigo à apresentação e discussão destes cursos.

\section{A psicologia nos cursos do Exército}

Iniciamos a análise dos cursos de psicologia citados no Boletim. Procuramos seus programas e bibliografias, muitas vezes não presentes nesse veículo, sendo necessário recorrer a outras fontes, como os arquivos da Escola de Aplicação do Serviço de Saúde do Exército, também depositados no AHEx, e a outras publicações, como o livro Psicologia militar, de autoria de Emilio Mira y López (1986-1964), publicado pela Editora Biblioteca do Exército em 1949, resultado de um curso oferecido pelo psiquiatra espanhol a militares do Exército.

Os resultados encontrados, embora se refiram principalmente ao Exército, confirmam uma trajetória esperada e já narrada por Carvalho (2012) em sua pesquisa sobre as revistas de Educação Física: a presença de uma psicologia difusa, mais no sentido de regras de bom comportamento impregnadas da moralidade da época

\footnotetext{
${ }^{3}$ Os pesquisadores ficam em uma sala onde há mesas e cadeiras, bem como luvas disponíveis para seu uso. Pede-se um dado material e o encarregado vai busca-lo. Ao final, deixa-se o material em cima da mesa para guarda pelo encarregado.
} 
(décadas de 1920 e 1930), à qual vai se agregando lentamente a psicologia científica, de forma mais vagarosa do que encontramos nos livros clássicos de história da psicologia, baseados na história desta disciplina nos Estados Unidos, mas coerente com o desenvolvimento da psicologia no Brasil, conforme os trabalhos a respeito já citados .

Assim, é importante lembrar que o uso massivo de testes psicológicos - a principal forma de demonstração da utilidade da psicologia (Rose, 2008) - começou com Robert Yerkes (1876-1956) durante a I Guerra Mundial, quando este psicólogo, eugenistae primatologista criou as baterias Army e Beta Tests para testagem dos soldados do Exército Americano. Entretanto, naquela época a maior influência no Exército Brasileiro ainda era a da França, que enviara uma missão militar ainda no começo do século. Treinamento e armamentos eram os temas presentes (Araújo, 2008). Somente a partir da II Guerra Mundial a influência estadunidense se estabeleceu de forma hegemônica. Assim, não é de se estranhar que os testes não estejam presentes neste primeiro momento e que haja maior influência de psicólogos europeus que estavam no Brasil.

Ao pesquisarmos os Boletins, o primeiro uso da psicologia encontrado nesse período foi a conferência sobre Psicologia Experimental, nas Escolas de Intendência e de Aplicação do Serviço de Saúde, ministrada pelo psicólogo polonês Waclaw Radecki, chefe do Laboratório de Psicologia da Colonia de Psicopatas do Engenho de Dentro desde 1923. Radecki ministrou, em seguida, um curso que foi publicado pela Escola de Serviço Social do Exército sob o título Tratado de Psicologia (Radecki, 1928/1929).De formação genebrina, com Édouard Claparède, Radecki era um dos poucos psicólogos atuantes no Brasil naquele momento, quando os interessados em psicologia ainda eram autodidatas. Sua presença mostra como o Exército estava atento às novidades teóricas, principalmente se vincularmos isto à criação, no mesmo ano, da Escola de Educação Física, onde encontramos forte presença da Psicologia (Carvalho, 2012). Muitas conferências foram ali realizadas, por Radecki, Emilio Mira y López (1896-1964), Lourenço Filho (1897-1970) e outros. Os médicos militares Agnello Ubirajara da Rocha (1896-1984), Arauld da Silva Bretas (1881-1971) e Alberto Guilherme Moore (1860-1968), talvez estimulados pelas conferências de Radecki, trabalharam com ele no Laboratório de Psicologia da Colônia de Psicopatas do Engenho de Dentro (Centofanti, 1982). O contato com Radecki, para além das conferências e cursos no Exército, pode ter sido provocado também pelos cursos de psicologia que ministrou na Faculdade de Medicina do Rio de Janeiro, quando Agnello da Rocha cursava medicina. É importante lembrar que, naquele momento, a comunidade médica do Rio de Janeiro era pequena, favorecendo o conhecimento comum. 
A par de seu interesse, a presença destes militares médicos no Laboratório dirigido por Radecki deveu-se à missão que receberam de fazer a inspeção de saúde nos candidatos a piloto militar para os quadros da Arma da Aviação do Exército, criada em 1927 (Lei no 5168, 1927, 13 de janeiro). Era necessária uma seleção mais especializada do que a que então se fazia; afinal, esses soldados receberiam treinamento dispendioso, e, igualmente, seus instrumentos de trabalhos, as aeronaves, são equipamentos caros.

A escolha do Laboratório de Psicologia da Colônia de Psicopatas para fazer parte da inspeção de saúde dos candidatos foi positiva, pois o Boletim do Exército No 572, de 10 de janeiro de 1930, informa que o Laboratório foi incluído entre os estabelecimentos em condições de receber médicos militares. Aqueles médicos citados escreveram artigos sobre os trabalhos que desenvolveram no Laboratório, que foram publicados nos Annaes da Colonia de Psychophatas de 1929. Ubirajara da Rocha escreveu Estudo da attenção nos aviadores (Rocha, 1929a) e Parte psychologica do relatório dos trabalhos referentes à selecção dos candidatos à aviação militar (Rocha, 1929b). De autoria de Alberto Moore encontramos Contribuição ao estudo psychotechnico dos automatismos (Moore, 1929). Já Arauld Bretas ${ }^{4}$ publicou Observação sobre um segmento (parte sensorial) do perfil psychologico do aviador (Bretas, 1929).

Na década de 1930, a psicologia deixou de ser só uma conferência presente nos cursos ministrados e começou a ser uma disciplina específica. Estes cursos são o objetivo deste texto, portanto aqui exporemos cada um dos realizados no período coberto por nossa investigação.

No ano de 1930, o Centro Militar de Educação Física apresentou um Plano de Ensino para o Curso de Instrutor de Educação Física, que seria composto de 15 matérias divididas em dois períodos (Ministério da Guerra, 1930, 31 de janeiro). Entre essas matérias estava a de Psicologia Aplicada, que deveria ser ministrada no segundo período. Agnello da Rocha foi designado para ser instrutor dessa disciplina. É importante ressaltar que, onze anos depois, o mesmo curso continuava apresentando a matéria de psicologia em seu Plano de Ensino (Ministério da Guerra, 1941, 26 de julho).

Em 1933 (Decreto n. 22.735, 1933, 19 de maio) foram criados os Serviços de Aviação do Exército, dentre eles o Serviço Médico da Aviação, no qual estava incluído o Departamento Médico de Aviação, unidade onde eram realizadas as inspeções de saúde regulares de militares e as inspeções de saúde dos candidatos à carreira da aviação militar. Neste Departamento foi instalado um Gabinete de Psicologia, o

\footnotetext{
4 Bretas foi transferido para a Força Aérea Brasileira, quando da criação desta em 1941, e também foi colaborador do Instituto de Seleção e Orientação Profissional (ISOP), dirigido por Mira y López.
} 
primeiro laboratório de psicologia que temos notícia dentro das Forças Armadas no Brasil. Seu primeiro diretor, o então Major Médico Angelo Godinho dos Santos (18881949) foi transferido, juntamente com Arauld Bretas e outros médicos militares do Exército e da Marinha do Brasil, para a Força Aérea Brasileira, tornando-se o primeiro Diretor de Saúde desta força, tendo sido consagrado como patrono do Quadro de Saúde da Aeronáutica em 1968 (Decreto n. 63.192, 1968, 29 de agosto). Em seu perfil na página web da Academia Brasileira de Medicina Militar, aparece a seguinte referência à psicologia:

Em 1937, como major médico do Exército, Godinho dos Santos dinamizo o Departamento Médico da Aviação Militar. Aí, aos poucos, liderou o desenvolvimento da nova especialidade -- a Medicina da Aviação. Formou especialistas que realizavam exames especializados de Fisiologia, Oftalmologia, Otorrinolaringologia, Radiologia e Psicologia, em gabinetes dotados do que havia de mais moderno. Realizou, pioneiramente, exames psicotécnicos em massa (Academia Brasileira de Medicina Militar, s.d., s.p.).

Neste Departamento, era oferecido o Curso de Especialização em Medicina da Aviação, necessário para os médicos atuarem em -bem como poderem chefiar - os cinco Gabinetes do Departamento, incluindo o Gabinete de Psicologia.

Em 1935, o Regulamento do Serviço Médico da Aviação Militar (Decreto n. 361, 1935, 3 de outubro) mostra a disciplina de Psicologia no programa do curso, com o nome de Psicologia Aplicada à Aviação. O programa desta matéria era divido em duas partes: teórica e aplicada. Na primeira, além de uma rápida contextualização histórica da psicologia e da filosofia, o programa apresentava a psicologia clássica que, segundo os instrutores, deveria ser dividida em três aspectos: vida intelectual, vida afetiva e vida volectiva (vontade). Na parte aplicada, o objetivo era o estudo da psicotécnica geral que, no programa, estava dividida em quatro tópicos: estudo das atividades humanas e análise dos tipos, seleção e orientação profissional, métodos de exame e perfis psicotécnicos e, por fim, prática de exames, aparelhos e testes. Vemos, pois, que a psicologia aqui presente é, em parte, ainda tomista, e se mescla aparentemente sem dificuldades com o modelo de psicologia aplicada e das teorias, principalmente as tipológicas, presentes naquele momento. Um sincretismo teórico que talvez possamos dizer seja também uma marca da apropriação brasileira de teorias estrangeiras.

Nada de muito diferente em relação ao que sucede no âmbito mais amplo da psicologia no país, embora a pequena produção editorial que começa a surgir, notadamente pelo trabalho de Lourenço Filho frente à Biblioteca da Educação, da Editora Melhoramentos, procurasse tornar presente a psicologia científica (Jacó-Vilela, 2012). 
Em 1942, a Escola de Estado Maior - cujo curso dura três anos - também incluiu em seu curso de a disciplina de psicologia, presente tanto no segundo como no terceiro anos. Nestes dois anos ela aparece dentro da disciplina de Cultura Geral, com ênfase sobretudo no estudo da psicotécnica aplicada à guerra (Ministério da Guerra, , 1942, 21 de novembro) o que é compreensível, tendo em vista que logo em seguida (em 1944) o Brasil ingressou na II Guerra Mundial, ao lado das potências contrárias ao nazismo. Deve-se assinalar não só que o Brasil foi o único país latino-americano que enviou tropas para a guerra que se travava principalmente na Europa, como também que, segundo diversos autores, esta participação na II Guerra foi de suma importância para o movimento de deposição de Getúlio Vargas em 1945 - a oposição a seu governo argumentava que, se lutávamos contra a ditadura, o fascismo, na Europa, por que deveríamos aceitar a ditadura entre nós? (Schwarcz \& Starling, 2015).

No final desta década, em 1949, na Escola de Instrução Especializada, dentre os assuntos a serem estudados pelos instrutores encontrava-se a psicologia experimental. A justificativa para o ensino desta disciplina, assim como para o ensino da pedagogia e da sociologia, destacava que a função deste profissional era a de um instrutor-educador (Ministério da Guerra, 1949, 4 de junho).

Por outro lado, neste mesmo ano, no Curso de Classificação de Pessoal, a psicologia aparecia pela primeira vez como disciplina estruturante de um curso (Ministério da Guerra, 1950, 13 de maio). Na organização geral de ensino, das quatro disciplinas propostas, duas são exclusivamente de psicologia, uma dialoga com a psicologia e somente uma não tem conexão com este conteúdo. São elas: Noções de Psicologia Normal e Patológica, Psicotécnica Militar, Estatística aplicada à Educação e à Psicologia e Legislação Militar.

Noções de Psicologia Normal e Patológica tem como objetivo fornecer as noções de normalidade e patologia necessárias aos oficiais classificadores de pessoal. 0 repertório é diverso. Assim, entre os temas encontram-se: objetivos e métodos da psicologia, a introspecção, métodos comparativos e métodos de laboratório, linguagem psicológica, medida em psicologia, classificação dos fatos psicológicos, atenção, funções gerais da consciência, psicofisiologia do esforço físico, memória, psicologia dos chefes militares, noções de biotipologia, personalidade psicopática etc.

A disciplina de Psicotécnica Militar, por sua vez, tem por finalidade ministrar noções fundamentais sobre o emprego da psicologia no campo das atividades militares, métodos de psicotécnica e suas relações com a organização do trabalho, a diferença psicológica entre as profissões, bem como proporcionar aos alunos a prática de classificação, seleção e orientação profissional militar. 
A terceira disciplina, denominada de Estatística Aplicada à Educação e à Psicologia, tem como objetivo ministrar noções sobre técnicas estatísticas necessárias a diversos aspectos, como: descrição quantitativa de graus de correlação entre medidas de diferentes traços psicológicos ou educacionais e determinação do grau de fidedignidade e validade dos resultados dos testes, escalas ou gabaritos de avaliação das diferentes individuais. Numa época em que não havia cursos de graduação em psicologia no nosso país, quando sequer a profissão de psicólogo era regulamenta por aqui, esses testes de avaliação psicológica eram aplicados por diferentes profissionais; no caso do Exército, por militares que faziam seleção de candidatos à carreira militar. ${ }^{5}$

Entretanto, se o programa deste Curso de Classificação de Pessoal aparentemente foge à psicotécnica, haja vista a disciplina de Psicologia Normal e Patológica, o conteúdo desta última mostra que a visão de mensuração e classificação, própria da psicotécnica, continua presente.

Em 1949, como anteriormente indicado, foi publicado o livro Psicologia militar, de Emilio Mira y López (1949), pela Editoria Biblioteca do Exército. Este livro resultou de curso que Emilio Mira ministrou para oficiais do Exército e trata de temas também pertinentes à psicotécnica, além de alguns outros mais vinculados a uma perspectiva psicossocial. Os temas são seleção, orientação, formação e recolocação de pessoal, rendimento na execução de tarefas, motivação (moral) da tropa em situações de guerra, administração de boatos, contrapropaganda, e relação entre os militares e os civis em tempos de paz e de guerra. Apresenta também o Psicodiagnóstico Miocinético (P.M.K.), teste desenvolvido por Mira y López, inicialmente para a avaliação de aviadores e depois utilizado para diversos fins, tanto na clínica, na escola, quanto na seleção de pessoal e na orientação profissional. Em muitos capítulos, traz, ao final, uma breve bibliografia de apoio.

Ressalte-se aqui que, desde a década de 1940, tornou-se relevante o estudo de temas de psicologia social, como a psicologia dos chefes militares. Isto é comprovado também por nossa pesquisa nas bibliotecas, onde se verifica, a partir desta época, a aquisição de livros de psicologia social ${ }^{6}$. Nossa hipótese é que esta mudança se relaciona com a participação do Brasil na II Guerra Mundial e a maior influência estadunidense a partir deste período, como já assinalado. Nos Estados Unidos, a partir do trabalho de Kurt Lewin (1890-1947) desde os anos de 1930, a psicologia social de

\footnotetext{
${ }^{5}$ Numa época em que não havia cursos de graduação em psicologia no nosso país, quando sequer a profissão de psicólogo era regulamenta por aqui, esses testes de avaliação psicológica eram aplicados por profissionais de diferentes formações; no caso do Exército, por militares que exerciam funções na seleção de candidatos à carreira militar. Esta é a base da constituição da função de "psicotécnico" no corpo militar do Exército.

${ }^{6}$ A literatura presente nas bibliotecas do Exército não é objeto deste artigo, por isto não nos detemos nela.
} 
base cognitivo-experimental teve um grande desenvolvimento e impacto social, ocupando talvez o papel do behaviorismo nos anos de 1930 naquele país. Certamente a mudança da orientação militar também produziu alterações na orientação teóricocientífica dos cursos. Entretanto, os temas de psicologia social se tornaram presentes inicialmente ainda numa forma psicotécnica, voltada para a avaliação e a classificação.

Dez anos depois, em 1959, destacam-se as alterações no regulamento da Academia Militar das Agulhas Negras, tradicional centro de ensino superior que forma oficiais combatentes das áreas de Infantaria, Cavalaria, Artilharia, Engenharia, Comunicações, Quadro de Material Bélico e Serviço de Intendência do Exército Brasileiro. A seleção para ingresso nessa academia implica em exames intelectuais, físicos, médicos e psicológicos. Notamos uma valorização destes quando se verifica que o resultado dos exames psicológicos entra como primeiro critério de desempate para a classificação, em caso de notas iguais nos exames intelectuais (Ministério da Guerra, 1959, 30 de maio).

Mais adiante, neste mesmo regulamento, encontram-se as disciplinas que serão oferecidas em cada um dos cursos. Para todos, encontramos duas disciplinas de Psicologia a serem cursadas no terceiro ano: Psicologia Geral e Psicologia das Relações Humanas no $1^{\circ}$ período e Psicologia Educacional no $2^{\circ}$ período.

Aqui verificamos que o tempo da psicotécnica chegou ao fim. A disciplina Psicologia já está relativamente estabelecida no país, com curso de graduação (o primeiro, da PUC-Rio, foi criado em 1953), com associações e revistas (no Rio e em São Paulo, criadas na década anterior) e, a partir do segundo ciclo de modernização protagonizado pelo Governo Juscelino Kubitscheck (1955-1960) bem como pelos efeitos da II Guerra Mundial, está mais articulada ao pensamento global, mais próxima do que se produz nos centros de conhecimento, que neste momento definitivamente se deslocara para os Estados Unidos.

Assim, o movimento de Relações Humanas pode se tornar presente no ensino do Exército. Curiosamente, parece que a influência mais direta não foi estadunidense, dos trabalhos de Elton Mayo nos anos de 1920-1930, mas francesa: em 1958, o então Banco da Lavoura de Minas Gerais criou seu Departamento de Orientação e Treinamento (DOT), chefiado por Pierre Weil (1924-2008) que trouxe uma perspectiva de relações humanas ao trabalho, até então só entendido sob o prisma da psicotécnica (Motta, 2004). Por outro lado, isto sem dúvida também é efeito da vitória recente dos países democráticos contra o Eixo. Pode-se verificar a pertinência do valor "democracia" quando vemos que, nos cursos da Academia Militar de Agulhas Negras, a primeira disciplina, Psicologia Geral e Psicologia das Relações humanas, visava capacitar o oficial para lidar com os problemas humanos que surgem no dia a dia da 
vida profissional, as diferenças individuais, bem como o conhecimento de técnicas democráticas de chefia. A disciplina pretendia formar essas capacidades através da discussão de alguns tópicos, como Correntes Psicológicas atuais, Personalidade, 0 Ajustamentos e seus problemas no meio Militar, O problema da Liderança e da Chefia, Psicologia e trabalho.

A disciplina de Psicologia Educacional, por sua vez, desenvolvia as capacidades de compreensão dos mecanismos de aprendizagem e do papel do educador neste processo. Alguns dos tópicos são Pedagogia e Psicologia, Psicologia Educacional conceito e objeto, O educando, O Educador, Fundamentos da didática da Instrução Militar.

Estes são os cursos que nosso levantamento encontrou. A partir da década de 1960 certamente muito mais cursos se fizeram presentes, principalmente por meio do Centro de Estudos de Pessoal (CEP), órgão do Exército criado em 1965 (situado no Forte Duque de Caxias, no Rio de Janeiro).

\section{Algumas considerações}

No processo de sua institucionalização no Brasil, embora se relate principalmente sua presença na Educação, a psicologia esteve presente em inúmeros outros campos Já temos algum conhecimento, por exemplo, de suas relações com a Igreja Católica (Jacó-Vilela \& Rocha, 2014) e com o Direito (Lourenço \& Campos, 2009). Este trabalho aponta sua presença no Exército Brasileiro.

Nos cursos de psicologia oferecidos aos oficiais do Exército, observou-se que a ênfase temática situava-se na psicologia experimental - inicialmente como experimentos no principal laboratório existente na época, o Laboratório de psicologia da Colonia de Psicopatas do Engenho de Dentro. Como em outras instituições, provavelmente pelo alto custo dos trabalhos experimentais, o espaço foi ocupado pela psicotécnica, com o uso de testes psicológicos na seleção e classificação de pessoal. Depois da II Guerra Mundial, é a vez da psicologia social, com o tema da liderança como o mais relevante.

Se consideramos que esta trajetória acompanha, no geral, uma história tradicional da psicologia que parte da psicologia experimental de Wundt e sua continuidade com Titchener, devemos também compreender as especificidades do caso brasileiro, não só em termos de distância temporal como, principalmente, nas formas nativas de desenvolvimento. É assim, portanto, que, junto a uma psicologia mais de acordo com os manuais, encontramos teorias biotipológicas (próprias da psicologia italiana), a discussão sobre a normalidade (muito presente na psicologia 
francesa) numa mescla que pode ser entendida como própria da psicologia que aqui se desenvolve.

Por outro lado, a situação de colonialidade faz com que as Forças Armadas - ou, no caso, especificamente o Exército - entendam que devem se aliar a determinados países para melhor defender a "soberania nacional". Esta aproximação ocorre não somente em termos de teorias e técnicas militares, pois se extrapola, como vimos, para as formas de compreender e lidar como as pessoas que constituem o Exército.

Tendo em vista a raridade de estudos sobre como a psicologia foi subsumida pelo Exército brasileiro, entende-se que são necessários mais estudos, atentando a outras minúcias do dia-a-dia desta Arma, bem como das outras não estudadas em nossa pesquisa, em suas diferentes diretorias e departamentos, para compreendermos melhor o que foi solicitado à psicologia e como os conteúdos e práticas desta foram assimilados e utilizados.

\section{Referências}

Academia Brasileira de Medicina Militar (s/a). Os patronos dos serviços de saúde das Forças Armadas. Recuperado de www.abmm.org.br/mil/biblioteca/artigos/343os-patronos-dos-servicos-de-saude-das-forcas-armadas.

Alves, C. B. \& Delmondez, P. (2015). Contribuições do pensamento decolonial à psicologia política. Psicologia Política, 15(34), 647-661.

Antunes, M. A. M. (1999). A psicologia no Brasil: leitura histórica sobre sua constituição. São Paulo: Edusp.

Antunes, M. A. M. (2002). Psicologia e educação em periódicos brasileiros anteriores a 1962. Psicologia Escolar e Educacional, 6(2), 193-200.

Araújo, R. N. (2008). A influência francesa dentro do Exército brasileiro (1930-1964): declínio ou permanência? Esboços, 15, 245-273.

Barros, J. A. (2004). Os campos da história: uma introdução às especialidades da história. Revista HISTEDBR, 16, 17-35.

Basalla, G. (1967). The spread of Western Science. Science, 156, 611-22.

Bretas, A. (1929). Observação sobre um segmento (parte sensorial) do perfil psychologico doaviador. Annaes da Colonia de Psychopatas do Engenho de Dentro, 317-354.

Campos, R. H. F. (2004). Prefácio. Em M. B. Lourenço Filho. Introdução ao Estudo da Escola Nova. Rio de Janeiro: EdUERJ. 
Carvalho, C. A. (2012). Psicologia do esporte no Brasil: história e nuances de sua constituição. Tese de doutorado, Programa de pós-Graduação em Psicologia Social, Universidade do Estado do Rio de Janeiro, Rio de Janeiro, RJ.

Centofanti, R. (1982). Radecki e a Psicologia no Brasil. Psicologia: Ciência e Profissão, 3(1), 2-50. dx.doi.org/10.1590/S1414-98931982000100001

Danziger, K. (1996). Towards a polycentric history of psychology. Paper presented at the 26th International Congress of Psychology in Montréal, Canada. Available at www.kurtdanziger.com/Paper\%209.pdf

De Certeau, M. (2000). A escrita da história (M. L. Menezes, Trad.). São Paulo: Forense Universitária. (Original publicado em 1975).

Decreto n. 63.192. (1968, 29 de agosto). Considera "Patrono do Serviço de Saúde da Aeronáutica" o Major Brigadeiro Médico Dr. Angelo Godinho dos Santos e estabelece o dia 11 de maio como data festiva nas Organizações do Serviço de Saúde da Aeronáutica. Brasília: Presidência da República. Recuperado em 8 de setembro, 2018, de www2.camara.leg.br/legin/fed/decret/1960-1969/decreto63192-29-agosto-1968-404486-publicacaooriginal-1-pe.html

Decreto n. 361. (1935, 03 de outubro). Aprova o regulamento para o Serviço Médico da Aviação Militar. Rio De Janeiro: Presidência da República. Recuperado em 8 de setembro, 2018, de www.lexml.gov.br/urn/urn:lex:br:federal:decreto:1935$10-03 ; 361$

Decreto n. 22.735. (1933, 19 de maio). Organização das Unidades e Serviços Aéreos do Exercito. Rio De Janeiro: Presidência da República. Recuperado em 8 de setembro, 2018, de www2.camara.leg.br/legin/fed/decret/1930-1939/decreto22735-19-maio-1933-519513-publicacaooriginal-1-pe.html

Fanon, F. (1968). Os condenados da terra. Rio de Janeiro: Civilização Brasileira.

Freyre, G. (1997). Casa grande \& senzala (20a ed.). Rio de Janeiro: José Olympio. (Original publicado em 1933).

Jacó-Vilela, A. M. (2009). Historiografia da psicologia no Brasil. Em J. Bernardes \& B. Medrado (Org.s). Psicologia social e políticas de existência: fronteiras e conflitos (pp. 125-138). Maceió: Abrapso.

Jacó-Vilela, A. M. (2012). História da psicologia no Brasil: uma narrativa por meio de seu ensino. Psicologia: Ciência e Profissão, 32(spe), 28-43. dx.doi.org/10.1590/S1414-98932012000500004

Jacó-Vilela, A. M. \& Rocha, L. F. D. (2014). Uma perspectiva católica da psicologia no Brasil: análise de artigos da revista "A Ordem". Psicologia em Pesquisa, 8(1), 115-126. dx.doi.org/DOI: 10.5327/Z1982-1247201400010011 
Leahey, T. H. (2005). Historia de la psicologia. Madrid: Pearson Educación.

Lei n. 5168 (1927, 13 de janeiro). Crêa a arma de Aviação do Exercito. Rio de Janeiro: Presidência da República. Recuperado em 8 de setembro, 2018, de www2.camara.leg.br/legin/fed/lei/1920-1929/lei-5168-13-janeiro-1927-563056publicacaooriginal-87165-pl.html

Lourenço, E. \& Campos, R. H. F. (2009). Temas psicológicos na revista da Faculdade de Direito da Universidade Federal de Minas Gerais. Temas em Psicologia, 17, 47-62.

Lourenço Filho, M. B. (2004). Introdução à Escola Nova. Rio de Janeiro: Eduerj. (Original publicado em 1930).

Ministério da Guerra. (1930, 31 de janeiro). Boletim do Exército, 576, 122.

Ministério da Guerra. (1941, 26 de julho). Boletim do Exército, 30, 2193.

Ministério da Guerra. (1942, 21 de novembro). Boletim do Exército, 47, 4307.

Ministério da Guerra. (1949, 4 junho). Boletim do Exército, 23, 1314.

Ministério da Guerra. (1950, 13 de maio). Boletim do Exército, 19.

Ministério da Guerra. (1959, 30 de maio). Boletim do Exército, s.n., 22.

Mira y Lopez, E. (1949). Psicologia militar. Rio de Janeiro: Biblioteca do Exército.

Monarcha, C. (2009). Brasil arcaico, Escola Nova: ciência, técnica e utopia nos anos 1920-1930. São Paulo: Unesp.

Moore, A. (1929). Contribuição ao estudo psychotechnico dos automatismos. Annaes da Colonia de Psychopatas do Engenho de Dentro, 381-392.

Motta, J. M. C. (2004). Fragmentos da história e da memória da psicologia no mundo do trabalho no Brasil: relações entre a industrialização e a psicologia. Tese de doutorado, Faculdade de Ciências Médicas, Universidade Estadual de Campos, Campos, RJ.

Nassif, L. E. \& Campos, R. H. F. (2005). Édouard Claparède (1873-1940): interesse, afetividade e inteligência na concepção da psicologia funcional. Memorandum, 9, 91-104. Recuperado em 8 de agosto, 2019, de periodicos.ufmg.br/index.php/memorandum/article/view/6749

Olinto, P. (2004). A psicologia experimental no Brasil. Em M. Antunes (Org.). História da psicologia no Brasil: primeiros ensaios. Rio de Janeiro: EdUerj. (Original publicado em 1944).

Penna, A. G. (1992). História da psicologia no Rio de Janeiro. Rio de Janeiro: Imago. 
Radecki, R. (1928/1929). Tratado de psicologia. Rio de Janeiro: Escola de Serviço Social do Exército.

Restrepo Forero, O. (2000). La sociologia del conocimiento científico o de cómo huir de la "recepción" y salir de la "periferia". Em D. Obregón (Org.) Culturas científicas y saberes locales: asimilación, hibridación, resistencia. Bogotá: Universidad Nacional de Colombia.

Rocha, U. (1929a). Estudo da attenção nos aviadores. Annaes da Colonia de Psychopatas do Engenho de Dentro, 355-380.

Rocha, U. (1929b). Parte psychologica do relatório dos trabalhos referentes à selecção dos candidatos à aviação militar. Annaes da Colonia de Psychopatas do Engenho de Dentro, 393-426.

Rosa, F. H. \& Hutz, C. S. (2008). Psicologia positiva em ambientes militares: bemestar subjetivo entre cadetes do Exército Brasileiro. Arquivos Brasileiros de Psicologia, 60(2), 157-171.

Rose, N. (2008). Psicologia como uma ciência social. Psicologia \& Sociedade, 20(2), 155-164. dx.doi.org/10.1590/S0102-71822008000200002

Safier, N. (2010). Global knowledge on the move: itineraries, Amerindian narratives and deep histories of science. Isis, 101(1), 133-145

Sanchis, P. (1995). Sincretismo e jogo das categorias: a propósito do Brasil, de Portugal e do Catolicismo. Psicologia Práticas Sociais, 2(1),23-56.

Sanchis, P. (2001). Fieis e cidadãos: percursos de sincretismo no Brasil. Rio de Janeiro: Eduerj.

Schwarcz, L. M. \& Starling, H. M. (2015). Brasil: uma biografia. São Paulo: Companhia das Letras.

Schwarz, R. (1977). As ideias fora do lugar. Em Schwarz, R. Ao vencedor as batatas (pp. 9-31). São Paulo: Duas Cidades.

Svasundaram, S. (2010). Introduction. Isis, 101(1), 95-97.

Spivak, G. (2010). Pode o subalterno falar? (A. Pereira, S. R. G. Almeida \& M. P. Feitosa, Trad.s). Belo Horizonte: UFMG. (Original publicado em 1985).

Stepan, N. (1976). Gênese e evolução da ciência no Brasil. Rio de Janeiro: Artenova. 


\section{Nota sobre as autoras}

Ana Maria Jacó-Vilela é professora titular do Instituto de Psicologia da Uerj, onde coordena o Laboratório de História e Memória da Psicologia Clio-Psyché. E-mail: jaco.ana@gmail.com

Dayse de Marie Oliveira é doutora em psicologia social. E-mail: dayse_marie@yahoo.com.br

Maíra de Souza Cerqueira dos Anjos é graduanda em psicologia. E-mail: mairadosanjos@gmail.com

Thaís Lohana Lins é graduada em psicologia. E-mail: thaislrlins@gmail.com

Data de recebimento: $13 / 01 / 2019$

Data de aceite: $31 / 08 / 2019$ 